\title{
Pyrethroid resistance in the major malaria vector Anopheles arabiensis in Nouakchott, Mauritania
}

\author{
Aichetou Mint Mohamed Lemine ${ }^{1,2}$, Mohamed Aly Ould Lemrabott ${ }^{1}$, El Hadji Amadou Niang 2,3, \\ Leonardo K. Basco ${ }^{4}$, Hervé Bogreau ${ }^{4,5}$, Ousmane Faye ${ }^{2}$ and Ali Ould Mohamed Salem Boukhary ${ }^{1,4^{*}}$
}

\begin{abstract}
Background: Mauritania is one of the African countries with ongoing malaria transmission where data on insecticide resistance of local malaria vectors are limited despite an increasing use of long-lasting insecticide-treated nets (LLINs) as the main intervention for vector control. This study presents an evaluation of the level of insecticide resistance of Anopheles arabiensis in Nouakchott.

Methods: Anopheles gambiae (s.l.) larvae were collected in breeding sites during the rainy season (August-September) in 2015 and 2016 from two selected sites in Nouakchott and reared until emergence. Adult anopheline mosquitoes were tested against malathion (5\%), bendiocarb (0.1\%), permethrin (0.75\%) and deltamethrin (0.05\%) using standard World Health Organization (WHO) insecticide-impregnated papers. PCR assays were used for the identification of An. gambiae (s.l.) sibling species as well as knockdown resistance ( $k d r)$.

Results: The mean knockdown times 50\% (KDT ${ }_{50}$ ) and 95\% (KDT ${ }_{95}$ ) were $66 \pm 17$ and $244 \pm 13$ min, respectively, for permethrin in 2015. The KDT 50 and the KDT 95 were $39 \pm 13$ and $119 \pm 13$ min, respectively, for deltamethrin. The KDT 50 and the KDT 95 doubled for both molecules in 2016. The mortality rates $24 \mathrm{~h}$ post-exposure revealed that An. arabiensis populations in Nouakchott were fully susceptible to bendiocarb and malathion in 2015 as well as in 2016, while they were resistant to permethrin (51.9\% mortality in 2015 and 24.1\% mortality in 2016) and to deltamethrin (83.7\% mortality in 2015 and 39.1\% mortality in 2016). The molecular identification showed that Anopheles arabiensis was the only malaria vector species collected in Nouakchott in 2015 and 2016. Both the West and East African kdr mutant alleles were found in An. arabiensis mosquitoes surviving exposure to pyrethroid insecticide, with a high rate of homozygous resistant genotypes (54.3\% for the West African $k d r$ mutation and $21.4 \%$ for the East African $k d r$ mutation) and a significant departure from Hardy-Weinberg proportions $\left(X^{2}=134, d f=3, P<0.001\right)$.

Conclusions: The study showed high levels of pyrethroid resistance in An. arabiensis populations in Nouakchott and presence of both West and East African $k d r$ alleles in the resistant phenotype. These results highlight a need for routine monitoring of susceptibility of malaria vector populations to insecticides used in public health programs.
\end{abstract}

Keywords: Pyrethroids, Insecticides, Resistance, kdr, Anopheles arabiensis, Nouakchott, Mauritania

\footnotetext{
* Correspondence: alimedsalem@gmail.com

${ }^{1}$ Unité de recherche Génomes et Milieux (JEAI), Université de Nouakchott

Al-Aasriya, Faculté des Sciences et Techniques, Nouveau Campus

Universitaire, Nouakchott, BP 5026, Mauritanie

${ }^{4}$ Aix Marseille Univ, IRD, AP-HM, SSA, VITROME, IHU-Méditerranée Infection,

Marseille, France

Full list of author information is available at the end of the article
}

(c) The Author(s). 2018 Open Access This article is distributed under the terms of the Creative Commons Attribution 4.0 International License (http://creativecommons.org/licenses/by/4.0/), which permits unrestricted use, distribution, and reproduction in any medium, provided you give appropriate credit to the original author(s) and the source, provide a link to the Creative Commons license, and indicate if changes were made. The Creative Commons Public Domain Dedication waiver (http://creativecommons.org/publicdomain/zero/1.0/) applies to the data made available in this article, unless otherwise stated. 


\section{Background}

Long-lasting insecticide-treated nets (LLINs) and indoor residual spraying (IRS), the most commonly used malaria vector control interventions, rely heavily on synthetic insecticides [1]. Currently, four chemical classes of insecticides are recommended by the World Health Organization Pesticide Evaluation Scheme (WHOPES) for use in public health programs: organochlorines, organophosphates, pyrethroids and carbamates [2]. Among these, pyrethroids are by far the most frequently used insecticides due to their relatively low toxicity to humans, fast knockdown effect and cost-effectiveness [3]. Moreover, pyrethroids are the only insecticides approved by the World Health Organization (WHO) for net impregnation [4]. Extensive use of insecticide-based interventions has led to massive reduction of malaria burden in many parts of Africa [5]. However, this strategy has subjected malaria vectors, in particular An. gambiae (sensu lato) which is the predominant Anopheles species in Africa, to selection pressures [6].

In Africa, resistance to DDT was first reported in 1967 in An. gambiae (s.l.) populations from Burkina Faso and hampered malaria eradication or control efforts led by the WHO since the 1950s. Anopheles funestus, the second major malaria vector in Africa, has also developed resistance to several insecticides in many parts of the African continent [6]. More recently, insecticide resistance in other vector species has been reported from many other countries [7]. According to the WHO, resistance to at least one insecticide class has been recorded in at least one anopheline species from nearly two-thirds of the countries with ongoing malaria transmission $[8,9]$. This continual selection of insecticide resistance and its geographical spread are threatening the gains made against the disease worldwide. Like the insecticide resistance among vectors, the resurgence of malaria and drug-resistant malaria parasites is a serious threat to current malaria control strategies and efforts to achieve the malaria elimination goal $[10,11]$. Pyrethroids have become the mainstay of mosquito control. Pyrethroids are neurotoxic chemicals that cause prolonged opening of the voltage-gated sodium channel of the neuron membrane, leading to increased nerve impulse transmission, paralysis, and eventual death of the insect [12]. Specific mutations in the gene coding for the voltage-gated sodium channel decrease neuronal sensitivity to pyrethroids, resulting in insecticide resistance [13]. This form of resistance, known as knockdown resistance $(k d r)$, is one of the most common mechanisms of resistance among insects, including anophelines [14-16]. Two point mutations occurring in codon 1014 of the voltage-gated para sodium channel gene have been associated with insecticide resistance in Anopheles gambiae (s.l.) in Africa [17]. These mutations result in either a leucine to phenylalanine (L1014F) substitution, referred to as West African $k d r$ mutation [18], or a leucine to serine substitution (L1014S), known as East African $k d r$ mutation $[19,20]$.

In Mauritania, malaria transmission is seasonal in most regions of the country [21, 22]. Plasmodium falciparum is the predominant malaria parasite in the southern Sahelian zone of the country, while Plasmodium vivax is more prevalent than P. falciparum in the northern Saharan zone [23-26]. A recent literature review indicated that 17 Anopheles species have been described throughout the country, among which An. gambiae (s.l.) is the most common and widespread species [27, 28]. Molecular identification of the $A n$. gambiae complex showed that $A n$. arabiensis is the main anopheline species in the country. Mint Lekweiry et al. [28] found only An. arabiensis in Nouakchott, the capital city of Mauritania that is located in the western Saharan region of the country. In the southeastern Sahelian zone of Hodh Elgharbi, this species accounted for only $40 \%$ of all the mosquitoes collected [28]. However, earlier studies have reported the predominance of $A n$. arabiensis $(97 \%, n=448)$ in Hodh Elgharbi (SF Traoré, unpublished WHO report, 2002). The presence of Anopheles coluzzii Coetzee \& Wilkerson (previously $\mathrm{M}$ form), another member of the An. gambiae complex, was also reported $(3 \%, n=13)$, but only in the Sahelian regions of Boghé and Aioun.

Mauritania is one of the African countries with ongoing malaria transmission where the resistance status of local malaria vectors to different insecticide classes is not well characterized [29]. The first study conducted in the Sahelian region of the country in 2002 reported a full susceptibility of $A n$. arabiensis to permethrin in Rosso, Boghe, Selibaby and Aioun and also full susceptibility of An. pharoensis to deltamethrin in Rosso and Boghe (Traore SF, unpublished WHO report, 2002). In 20092010, the presence of both the West and East African $k d r$ mutant alleles was first reported in An. gambiae (s.l.) populations in Mauritania [28].

The official published data reported the distribution of 165,000 LLINs in Mauritania from 2004 to 2005 [30]. In 2016, over 200,000 LLINs were distributed nationwide, thus substantially increasing bed-net ownership throughout the country. It is now estimated that more than $60 \%$ of the population owns at least one bednet (National Malaria Control Program, unpublished data). Therefore, with the scaling up of the distribution and increasing use of LLINs in Mauritania as well as the widespread occurrence of pyrethroid resistance in malaria vectors reported from several West and East African countries, there is an urgent need to establish the current status of insecticide resistance of the main malaria vectors in the country and assess the impact of insecticide-based vector control interventions [28, 31]. 
In the present study, we assessed the resistance status of An. arabiensis populations collected from two districts in Nouakchott to four insecticides used in public health programs. This data fills a gap in our knowledge and will improve current and future vector control strategies in Mauritania.

\section{Methods}

\section{Study sites and mosquito collection}

Entomological surveys were carried out during the wet season (August-September) in 2015 and 2016 in two selected sites in Nouakchott: Lycée de Teyarett $\left(18^{\circ} 07^{\prime} 37^{\prime \prime} \mathrm{N}\right.$, $\left.15^{\circ} 56^{\prime} 14^{\prime \prime W}\right)$ and Carrefour Ould Badou (18 $07^{\prime} 07^{\prime \prime N}$, $15^{\circ} 55^{\prime} 29^{\prime \prime W}$ ) (Fig. 1). In these areas, breeding sites mainly consisted of water discharged from public standpipes. The physical and chemical characteristics of the habitats of $A n$. gambiae (s.l.) in Nouakchott are published elsewhere [31].

In each study site, two larval habitats were sampled. Larvae and pupae of Anopheles mosquito were collected using the "dipping" sampling method and reared in the insectarium to adulthood. Larvae were kept in separate labelled bottles and transported to the insectary. Anopheles larvae were separated from mosquito larvae of the genera Aedes and Culex. Mosquito larvae of Anopheles spp. were placed in sterile plastic cups filled with water and maintained at a relative humidity of $75 \pm 5 \%$ and a temperature of $28 \pm 3{ }^{\circ} \mathrm{C}$ in our laboratory. They were fed with commercially available flakes of fish food $\left(\right.$ Tetramin $\left.^{\mathrm{TM}}\right)$. Adult mosquitoes that emerged from the pupae were transferred to a cage and fed with $10 \%$ sugar solution. Prior to exposure to insecticides, adult mosquitoes were randomly collected from cages and identified morphologically as An. gambiae (s.l.). Insecticide susceptibility tests were performed on unfed adult females aged from 3 to 5 days. After $24 \mathrm{~h}$, species identification of all dead mosquitoes and knocked-down surviving mosquitoes by PCR confirmed that they were all $A n$. gambiae (s.l.).

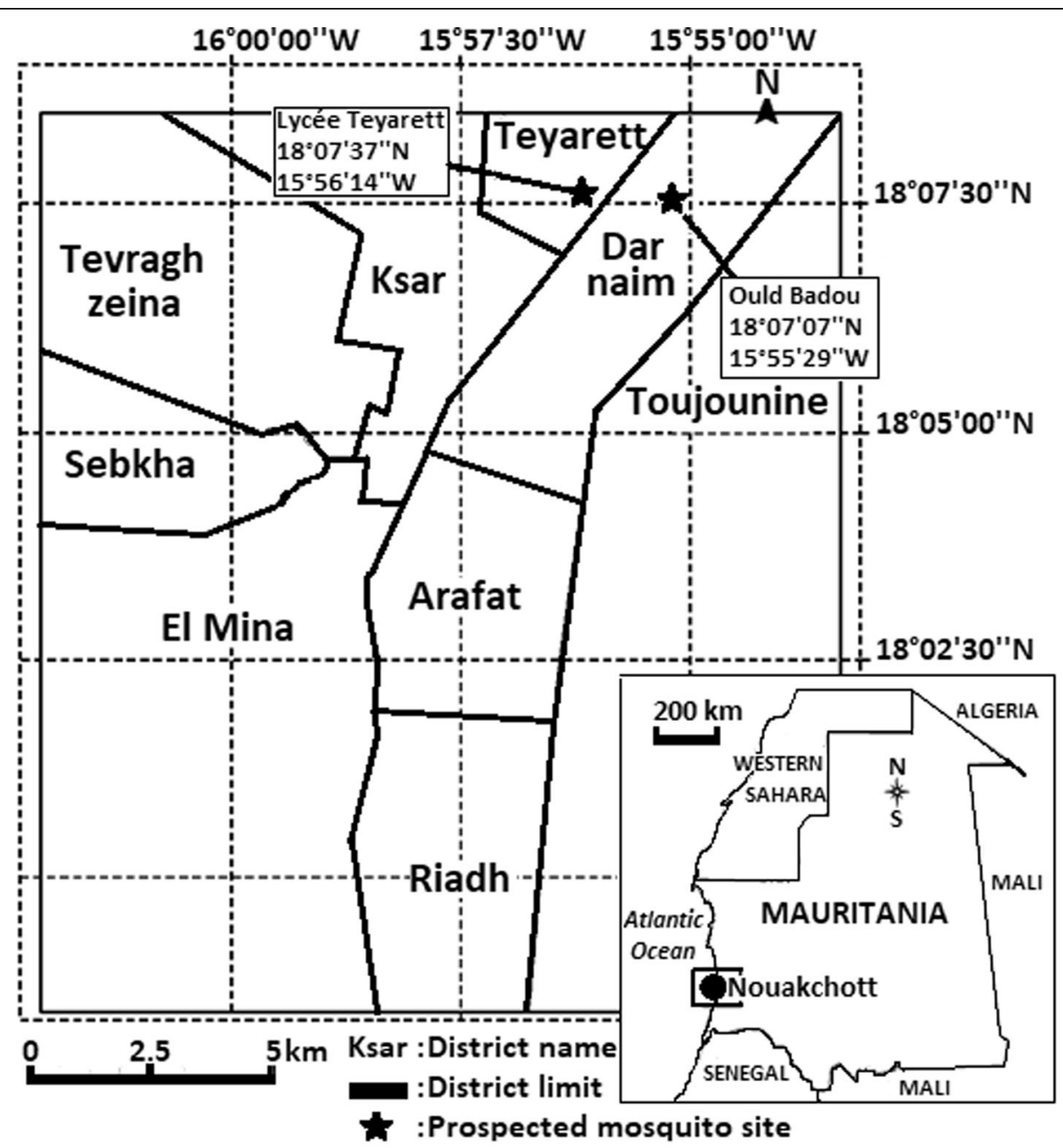

Fig. 1 Map showing the study sites in Nouakchott. Inset: map of Mauritania 


\section{Insecticide susceptibility tests}

Bioassays were performed using the WHO protocol for adult mosquitoes [32]. Quality-controlled (ISO 9001:2015 certified) impregnated papers were prepared according to the standardized WHO procedures using analytical grade of PESTANAL ${ }^{\oplus}$ insecticide solutions (Sigma-Aldrich, SaintQuentin Fallavier, France) and validated using insecticidesusceptible Kisumu strain of An. gambiae at the laboratory of Maladies Infectieuses et Vecteurs: Ecologie, Génétique, Evolution et Contrôle (MIVEGEC, Institut de Recherche pour le Développement, Montpellier, France). Four different insecticides representing three of four chemical classes available for public health applications against adult mosquitoes were used at the following discriminating concentrations: pyrethroids permethrin (0.75\%) and deltamethrin $(0.05 \%)$, organophosphate malathion $(5 \%)$ and carbamate bendiocarb $(0.1 \%)$. WHO tube tests were performed with batches of 20-25 unfed female An. gambiae (s.l.) mosquitoes aged 3-5 days by exposing them to insecticide-impregnated paper for one hour at $25 \pm 2{ }^{\circ} \mathrm{C}$ and $70-80 \%$ relative humidity. The number of knocked down mosquitoes was recorded at 10, 15, 20, 30, 40, 50 and $60 \mathrm{~min}$ before mosquitoes were transferred into holding tubes and provided with cotton wool soaked with $10 \%$ sucrose solution. Mortalities were recorded $24 \mathrm{~h}$ post-exposure. Batches of 50 mosquitoes exposed to paper impregnated with acetone/olive oil (for bendiocarb and malathion) and acetone/silicone (for permethrin and deltamethrin) were used as control groups.

For each insecticide, dead and live mosquitoes and mosquitoes in the control group were kept separately in $1.5 \mathrm{ml}$ microtubes over silica gel for molecular analysis. The results of the insecticide susceptibility test were validated if mortality in the control group was less than $5 \%$ and excluded if the mortality in the control group was more than $20 \%$. The mortality rate between 5 and $20 \%$ was corrected using Abbott's formula [33].

\section{DNA extraction, species identification and detection of kdr mutations}

Sub-samples of surviving female mosquitoes (alive after $24 \mathrm{~h}$ exposure) and control mosquitoes were randomly selected for molecular analysis. Genomic DNA was extracted from single mosquitoes following the cetyl trimethylammonium bromide (CTAB) protocol described by Le Goff et al. [34], re-suspended in $200 \mu \mathrm{l}$ of $1 \times$ tris-ethylene diamine tetra acetic acid (EDTA) buffer and stored at $-20{ }^{\circ} \mathrm{C}$. Anopheles gambiae (s.l.) species-specific identification was performed in 250 randomly selected specimens using the short interspersed elements (SINE) PCR described by Santolamazza et al. [35], which allows simultaneous discrimination of all members of the $A n$. gambiae complex. The West and East African $k d r$ mutations in An. arabiensis populations were genotyped using the intentional mismatch primer method described by MR4 staff and Huynh [36]. For mosquito genotyping the following allelic designation were used: $\mathrm{Rw}$, west resistant allele; Re, east resistant allele; and $S$, susceptible allele.

\section{Data analysis}

WHO criteria were used to evaluate the resistance/ susceptibility status of the tested mosquito populations [32]. Mortality rates were compared using a Chi-square test, assuming the normality of data when parametric tests were used. Knockdown times (50\% or median knockdown time, $\mathrm{KDT}_{50}$; and $90 \%$ knockdown time, $\mathrm{KDT}_{90}$ ) were determined using the log-probit regression model. Genotypic frequencies of West (L1014F) and East African (L1014S) $k d r$ mutations in mosquito population were compared to Hardy-Weinberg expectations using Pearson's chi-square test. Statistical analyses were performed using MedCalc software (Mariakerke, Belgium) [37]. A probability value of 0.05 or less was considered as significant.

\section{Results \\ Knockdown time}

The knockdown times were assessed for permethrin $0.75 \%$ and deltamethrin $0.05 \%$ in 2015 and 2016. In 2015, 50 and 95\% of the specimens of An. arabiensis exposed to permethrin $0.75 \%$ were knocked down after 66 min $\left(\mathrm{KDT}_{50}\right.$ ranging 53-79 $\left.\mathrm{min}\right)$ and after $244 \mathrm{~min}\left(\mathrm{KDT}_{95}\right.$ ranging 231-258 min), respectively. Comparatively, both the $\mathrm{KDT}_{50}$ and the $\mathrm{KDT}_{95}$ of the study population were shorter with deltamethrin at $39 \mathrm{~min}$ (26-52 $\mathrm{min}$ ) and $119 \mathrm{~min}$ (106-132 $\mathrm{min}$ ), respectively (Table 1$)$. In 2016, the knockdown times of 50 and $95 \%$ almost doubled for both insecticides (Table 1).

\section{Twenty-four hours post-exposure mortality}

Overall, 1494 An. gambiae (s.l.) were tested for insecticide resistance (702 in 2015 and 792 in 2016). The mortality rate in the control group was less than $5 \%$ for all the tests. Therefore, no corrections were required in the test groups. The bioassay showed that An. gambiae (s.l.) populations from both study sites were highly resistant to permethrin $(0.75 \%)$ and deltamethrin $(0.05 \%)$, with mortality rates of 51.9 and $83.7 \%$ in 2015 , and 24.1 and $39.1 \%$ in 2016 , respectively (Table 2). The mortality rate in 2016 for permethrin was significantly lower than that observed in $2015\left(\chi^{2}=31.5, d f=1, P<0.001\right)$. A similar trend was observed for deltamethrin $\left(\chi^{2}=81.1\right.$, $d f=1, P<0.001)$. The overall mortality rate associated with deltamethrin exposure was significantly higher than that for permethrin (62 vs 37.2\%; $\chi^{2}=47.3, d f=1$, $P<0.001$ ). All studied populations of An. gambiae (s.l.) were fully susceptible ( $100 \%$ mortality) to malathion (2\%) and bendiocarb (0.1\%) in both 2015 and 2016. 
Table 1 Knockdown times of An. arabiensis populations exposed to deltamethrin and permethrin in Nouakchott

\begin{tabular}{lllll}
\hline Insecticide & Year & No. of mosquitoes tested & KDT $_{50}$ (range) in min & KDT $_{95}$ (range) in min \\
\hline Permethrin (0.75\%) & 2015 & 181 & 66 (53-79) & 244 (231-258) \\
& 2016 & 203 & $117(104-131)$ & $489(475-502)$ \\
Deltamethrin (0.05\%) & 2015 & 197 & $39(26-52)$ & $119(106-132)$ \\
& 2016 & 189 & $78(65-91)$ & $257(244-270)$ \\
\hline
\end{tabular}

Abbreviations: $K D T_{50} 50 \%$ knockdown time, $K D T_{95} 95 \%$ knockdown time

\section{Species identification and $k d r$ genotyping}

Of 250 specimens confirmed to be An. arabiensis by molecular identification, 70 that survived exposure to insecticides and 15 control female mosquitoes were genotyped for $k d r$ mutations. Both West and East African $k d r$ resistant alleles were found among the tested specimens. The wild-type and three of five expected $k d r$ genotypes were observed among An. arabiensis mosquitoes that survived exposure to insecticides (Fig. 2). Heterozygous resistant east-west (ReRw) and heterozygous resistant east $(\mathrm{ReS})$ genotypes were not observed. The homozygous resistant west (RwRw) was the most frequent genotype $(54.3 \%, 38 / 70)$, followed by the wild-type homozygous susceptible (SS, 22.8\%, 16/70) and the homozygous resistant east (ReRe, $21.4 \%, 15 / 70)$. Only one mosquito (1/70, 1.4\%) was heterozygous (RwS) for the West African $k d r$ mutation. Nevertheless, the comparison of the observed and expected genotypic frequencies showed a significant departure from Hardy-Weinberg proportions $\left(\chi^{2}=134\right.$, $d f=3, P<0.001)$. This is likely associated with a deficit in heterozygotes as shown by an inbreeding coefficient $\left(F_{i s}\right)$ of 0.97 according to Weir \& Cockerham [38].

\section{Discussion}

Previous entomological studies highlighted the widespread presence of An. arabiensis in Mauritania [28]. The present study confirmed that An. arabiensis is the main malaria vector in Nouakchott and updated data on its susceptibility to four main insecticides used in public health programs. Our results showed that An. arabiensis populations are highly resistant to pyrethroids (permethrin and deltamethrin) but fully susceptible to malathion and bendiocarb in both sites during the study period. This finding is in agreement with the increasing selective pressure on mosquito populations due to the scaling-up of LLINs in the country (National Malaria Control Program, unpublished data), especially in urban areas such as Nouakchott. In Senegal, Niang et al. [39] have reported a dissimilar trend of knockdown dynamic between deltamethrin and permethrin, which they attributed to the more recent use of deltamethrin in comparison with permethrin in their study area, in addition to the known chemical difference of the two molecules (type I $v s$ type II) [39]. These authors have hypothesized that the introduction of bednets impregnated with deltamethrin $\left(\right.$ Olyset $\left.\mathrm{Net}^{(}\right)$in the study area in Senegal in the 1990s could have exerted strong insecticidal pressures on mosquitoes, giving rise to high levels of insecticide resistance. However, a previous study on a knockdown resistance-free $A n$. arabiensis population from Chad in Central Africa has reported a partial pyrethroid resistance (resistance to permethrin but not to deltamethrin) in $A n$. arabiensis field populations involving metabolic mechanisms of resistance with over-expressed P450 CYP6P4 [40]. By contrast, in Senegalese and Mauritanian Anopheles populations, the $k d r$-mediated target site resistance seems to be the main mechanism involved. However, the involvement of metabolic mechanisms of resistance could not be ruled out since $22.8 \%$ (16/70) of individuals characterized by the presence of $k d r$ mutations did not harbor any of the mutant alleles despite being fully resistant to pyrethroids. The same situation has been previously reported in some malaria vector populations from Senegal [39]. Multiple mechanisms of insecticide resistance in Anopheles gambiae (s.l.) populations have also been reported elsewhere in An. arabiensis [41]. There is a need to assess the potential involvement of metabolic mechanisms of resistance in west African populations of An. arabiensis, especially in the Mauritanian population, to explain the increase in the survival rate of $A n$. arabiensis populations

Table 2 Mortality rates of female An. arabiensis after $24 \mathrm{~h}$ exposure to four insecticides in 2015 and 2016 in Nouakchott

\begin{tabular}{|c|c|c|c|c|c|c|}
\hline \multirow[t]{2}{*}{ Insecticide } & \multicolumn{2}{|l|}{2015} & \multicolumn{2}{|l|}{2016} & \multirow[t]{2}{*}{$x^{2}$} & \multirow[t]{2}{*}{$P$} \\
\hline & n (\# replicate) & Mean mortality (\%) (95\% Cl) & n (\# replicate) & Mean mortality (\%) (95\% Cl) & & \\
\hline Permethrin (0.75\%) & $181(9)$ & $51.9(44.7-59.1)$ & $203(10)$ & $24.1(18.8-30.5)$ & 31.5 & $<0.001$ \\
\hline Deltamethrin (0.05\%) & $197(8)$ & 83.7 (77.9-88.2) & $189(9)$ & $39.1(32.5-46.3)$ & 81.1 & $<0.001$ \\
\hline Bendiocarb (0.1\%) & $106(5)$ & 100 & $203(10)$ & 100 & - & - \\
\hline Malathion (2\%) & $218(10)$ & 100 & $197(8)$ & 100 & - & - \\
\hline
\end{tabular}




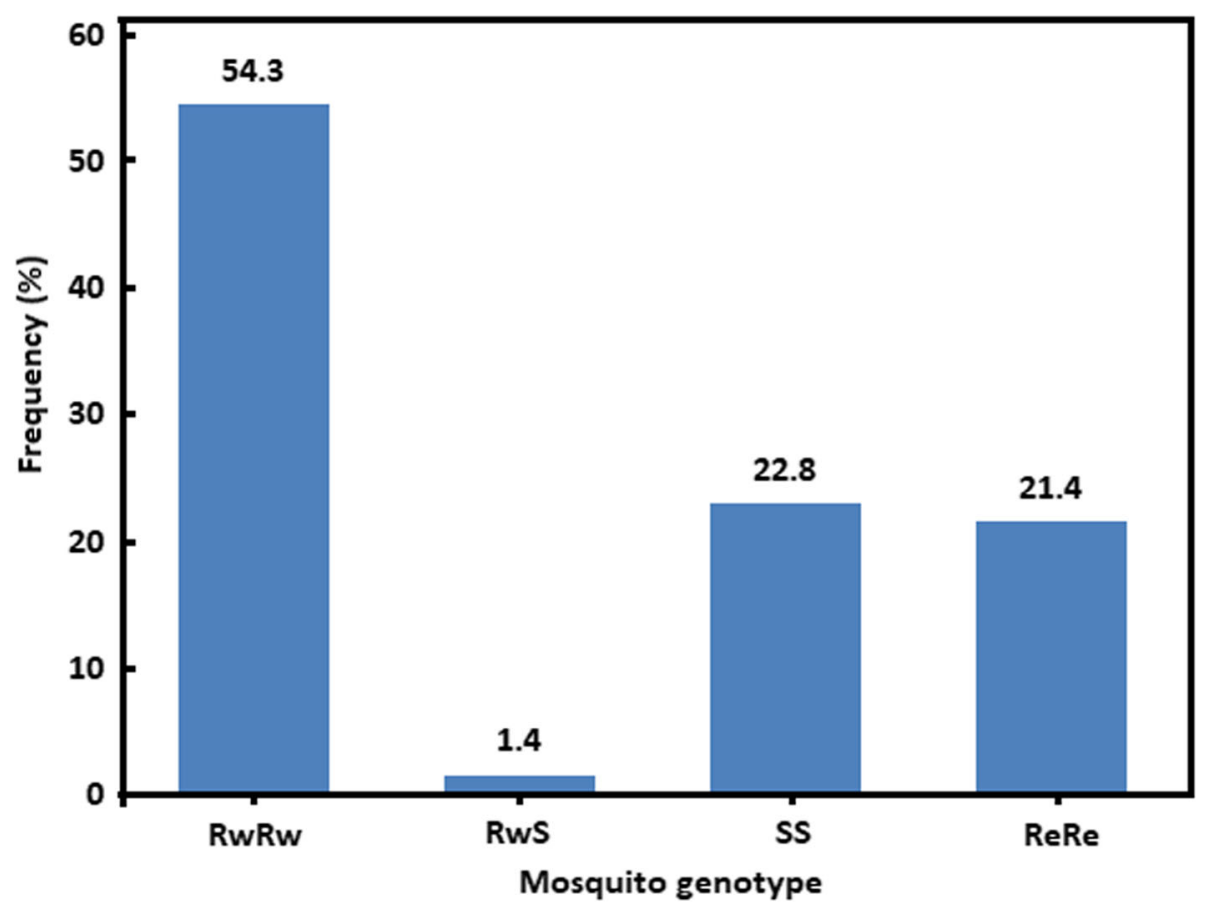

Fig. 2 Distribution of genotypic frequencies of kdr mutations among An. arabiensis mosquitoes surviving insecticide exposure. Abbreviations: RwRw, west homozygous resistant; RwS, west heterozygous resistant; SS, homozygous susceptible; ReRe, east homozygous resistant

exposed to pyrethroids in 2016 (mortality rate for permethrin $=24.1 \%$ and deltamethrin $=39.1 \%)$, compared to 2015 (mortality rate for permethrin $=51.9 \%$ and deltamethrin $=83.7 \%$ ).

Both the West and East African $k d r$ mutations were found in the two study sites in Nouakchott, with the West African $k d r$ being significantly more prevalent. This finding is in agreement with the general distribution pattern and frequencies of $k d r$ mutations in West Africa as shown in the distribution maps of pyrethroid-resistance and underlying mechanisms in African malaria vector [6]. However, a previous study in Nouakchott reported only the presence of the East African $k d r$ allele in An. arabiensis populations in 2009-2010 [28]. The presence of East African $k d r$ allele among $A n$. gambiae complex, particularly $A n$. arabiensis, is increasingly being observed in several West African countries, such as Benin [42], Burkina Faso [43] and Senegal [44]. The analysis of observed genotypic frequencies revealed a heterozygote deficit for the West African $k d r$ allele. Similar data were reported for $A n$. gambiae (s.l.) from many sites in Burkina Faso [45]. As suggested by several authors, exposure to insecticides used in agriculture, forest exploitation and public health purposes may confer selective advantages to resistant homozygote individuals because $k d r$ mutations are a recessive trait [46]. In Nouakchott, the widespread use of pyrethroids within households and for public health programs (LLIN mass distribution campaigns) may induce selection of resistant mosquitoes. The evidence for resistance in $A n$. arabiensis to two pyrethroid insecticides (deltamethrin and permethrin) in Nouakchott is of concern and may become an obstacle to successful malaria vector control.

Although the present study is highly informative, there is clearly a need to carry out further studies with larger populations of mosquitoes from different breeding sites, and with more insecticides, to establish a clearer picture of resistance and its molecular basis. Nevertheless, the results of this study should alert health policy makers to the alarming situation of insecticide resistance in $A n$. arabiensis, the major malaria vector in Nouakchott where more than one-fourth of the total population of Mauritania resides.

\section{Conclusions}

The study showed a high level of pyrethroid resistance in An. arabiensis populations in Nouakchott with a significant increase in the frequency of mutant $k d r$ compared to what was observed earlier in Nouakchott. These results stress the need for routine monitoring of the resistance status of malaria vector populations to insecticides in use in the public health sector.

\section{Abbreviations}

s.l.: sensu lato; kdr: Knockdown resistance; PSC: Pyrethrum space-spray catch; WHO: World Health Organization; LLINs: Long-lasting insecticide-treated nets; IRS: Indoor residual spraying; Rw: West resistant alleles; Re: East resistant allele; S: Susceptible allele 


\section{Acknowledgements}

The authors are grateful to the staff of IRD-MIVEGEC in Montpellier who supplied the quality-controlled impregnated papers used in the bioassays and the staff of the Laboratoire d'Ecologie Vectorielle of the University of Cheikh Anta-Diop in Dakar, Senegal, where molecular analyses were carried out.

\section{Funding}

This work was supported by research grants from Expertise France (Initiative 5\% grant) and the French National Research Institute for Sustainable Development [Institut de Recherche pour le Développement (IRD), JEAl grant].

\section{Availability of data and materials}

All data generated or analyzed during this study are included in this published article.

\section{Authors' contributions}

AMML, MAOL and AOMSB conceived and designed the study. AMML and MAOL carried out field collections and performed the experiments. AMML, EAN and $A O M S B$ analyzed the data. EAN, $L B, H B$, OF and AOMSB drafted the manuscript and critically revised the manuscript. All authors read and approved the final manuscript.

\section{Ethics approval and consent to participate}

Not applicable.

\section{Competing interests}

The authors declare that they have no competing interests.

\section{Publisher's Note}

Springer Nature remains neutral with regard to jurisdictional claims in published maps and institutional affiliations.

\section{Author details}

'Unité de recherche Génomes et Milieux (JEAI), Université de Nouakchott Al-Aasriya, Faculté des Sciences et Techniques, Nouveau Campus Universitaire, Nouakchott, BP 5026, Mauritanie. 'Laboratoire d'Ecologie Vectorielle et Parasitaire, Faculté des Sciences et Techniques, Université Cheikh Anta Diop, Dakar, Sénégal. ${ }^{3}$ Aix Marseille Univ, IRD, AP-HM, MEPHI, IHU-Méditerranée Infection, Marseille, France. ${ }^{4}$ Aix Marseille Univ, IRD, AP-HM, SSA, VITROME, IHU-Méditerranée Infection, Marseille, France. ${ }^{5}$ Institut de Recherche Biomédicale des Armées, Unité de Parasitologie et d'Entomologie, IHU-Méditerranée Infection, Marseille, France.

Received: 18 July 2017 Accepted: 29 May 2018

Published online: 13 June 2018

\section{References}

1. WHO. WHO recommended insecticides for indoor residual spraying against malaria vectors. 2015. http://www.who.int/whopes/Insecticides_IRS_2_ March_2015.pdf. Accessed 10 Dec 2017

2. WHO. World Malaria Report 2017. Geneva: World Health Organization; 2017.

3. Ngufor C, Tungu P, Malima R, Kirby M, Kisinza W, Rowland M. Insecticidetreated net wall hangings for malaria vector control: an experimental hut study in north-eastern Tanzania. Malar J. 2014;13:366.

4. WHO. WHO recommended long-lasting insecticidal nets. 2017. http://www. who.int/whopes/Long-lasting_insecticidal_nets_June_2017.pdf. Accessed 10 Nov 2017.

5. Killeen GF. A second chance to tackle African malaria vector mosquitoes that avoid houses and don't take drugs. Am J Trop Med Hyg. 2013;88:809-16

6. Dia I, Guelbeogo MW, Ayala D. Advances and perspectives in the study of the malaria mosquito Anopheles funestus. In: Manguin S, editor. Anopheles mosquitoes - new insights into malaria vectors. Rijeca: InTech; 2013. https://doi.org/10.5772/55389.

7. Corbel V, N'Guessan R. Distribution, mechanisms, impact and management of insecticide resistance in malaria vectors: A pragmatic review. In: Manguin S, editor. Anopheles mosquitoes - new insights into malaria vectors. Rijeca: InTech; 2013. https://doi.org/10.5772/56117.

8. Ranson H, N'guessan R, Lines J, Moiroux N, Nkuni Z, Corbel V. Pyrethroid resistance in African anopheline mosquitoes: what are the implications for malaria control? Trends Parasitol. 2011;27:91-8.
9. WHO. Global plan for insecticide resistance management in malaria vectors. Geneva: World Health Organization; 2012

10. Sougoufara S, Doucouré S, Sembéne PMB, Harry M, Sokhna C. Challenges for malaria vector control in sub-Saharan Africa: resistance and behavioral adaptations in Anopheles populations. J Vector Borne Dis. 2017;54:4-15.

11. Hemingway J, Field L, Vontas J. An overview of insecticide resistance. Science. 2002;298:96-7.

12. Bass C, Nikou D, Donnelly MJ, Williamson MS, Ranson H, Ball A, et al. Detection of knockdown resistance (kdr) mutations in Anopheles gambiae: a comparison of two new high-throughput assays with existing methods. Malar J. 2007;6:111.

13. Soderlund DM, Bloomquist JR. Molecular mechanisms of insecticide resistance. In: Roush RT, Tabashnik BE, editors. Pesticide resistance in arthropods. New York: Chapman and Hall; 1990. p. 58-96.

14. Brengues C, Hawkes NJ, Chandre F, McCarroll L, Duchon S, Guillet P, et al. Pyrethroid and DDT cross-resistance in Aedes aegypti is correlated with novel mutations in the voltage-gated sodium channel gene. Med Vet Entomol. 2003:17:87-94.

15. Dykes CL, Kushwah RBS, Das MK, Sharma SN, Bhatt RM, Veer V, et al. Knockdown resistance ( $k d r)$ mutations in Indian Anopheles culicifacies populations. Parasit Vectors. 2015;8:333.

16. Bkhache M, Tmimi FZ, Charafeddine O, Faraj C, Failloux AB, Sarih M. First report of L1014F-kdr mutation in Culex pipiens complex from Morocco. Parasit Vectors. 2016;9:644.

17. Silva APB, Santos JMM, Martins AJ. Mutations in the voltage-gated sodium channel gene of anophelines and their association with resistance to pyrethroids - a review. Parasit Vectors. 2014;7:450.

18. Martinez-Torres D, Chandre F, Williamson M, Darriet F, Berge J, Devonshire A, et al. Molecular characterization of pyrethroid knockdown resistance (kdr) in the major malaria vector Anopheles gambiae s.s. Insect Mol Biol. 1998:7:179-84

19. Ranson H, Jensen B, Vulule JM, Wang X, Hemmingway J, Collins FH. Identification of a point mutation in the voltage-gated sodium channel gene of Kenyan Anopheles gambiae associated with presence of DDT and pyrethroids. Insect Mol Biol. 2000;9:491-7.

20. Pinto J, Lynd A, Vicente JL, Santolamazza F, Randle NP, Gentile G, et al. Multiple origins of knockdown resistance mutations in the Afrotropical mosquito vector Anopheles gambiae. PLoS One. 2007;2:e1243.

21. Jelinek T, Aida AO, Peyerl-Hoffmann G, Jordan S, Mayor A, Heuschkel C, et al. Diagnostic value of molecular markers in chloroquine resistant falciparum malaria in southern Mauritania. Am J Trop Med Hyg. 2002;67:449-53.

22. Mint Lekweiry K, Ould Ahmedou Salem MS, Basco LK, Briolant S, Hafid JE, Ould Mohamed Salem Boukhary A. Malaria in Mauritania: retrospective and prospective overview. Malar J. 2015;14:100.

23. Mint Lekweiry K, Basco LK, Ould Ahmedou Salem MS, Hafid JE, Marin-Jauffre A, Ould Weddih A, et al. Malaria prevalence and morbidity among children reporting at health facilities in Nouakchott, Mauritania. Trans R Soc Trop Med Hyg. 2011;105:727-33.

24. Ould Ahmedou Salem MS, Basco LK, Ouldabdellahi M, Mint Lekweiry K, Konate $\mathrm{L}$, Faye $\mathrm{O}$, et al. Malaria-associated morbidity during the rainy season in Saharan and Sahelian zones in Mauritania. Acta Trop. 2015;152:1-7.

25. Ouldabdallahi Moukah M, Ba O, Ba H, Ould Khairy ML, Faye O, Bogreau H, et al. Malaria in three epidemiological strata in Mauritania. Malar J. 2016;15:204.

26. Ba H, Duffy CW, Ahouidi AD, Deh YB, Diallo MY, Tandia A, et al. Widespread distribution of Plasmodium vivax malaria in Mauritania on the interface of the Maghreb and West Africa. Malar J. 2016;15:80.

27. Mint Mohamed Lemine A, Ould Lemrabott MA, Ebou MH, Mint Lekweiry K, Ould Ahmedou Salem MS, Ould Brahim K, et al. Mosquitoes (Diptera: Culicidae) in Mauritania: a review of their biodiversity, distribution and medical importance. Parasit Vectors. 2017;10:35.

28. Mint Lekweiry K, Ould Ahmedou Salem MS, Cotteaux-Lautard C, Jarjaval F, Marin-Jauffre A, Bogreau H, et al. Circumsporozoite protein rates, blood-feeding pattern and frequency of knockdown resistance mutations in Anopheles spp. in two ecological zones of Mauritania. Parasit Vectors. 2016;9:268.

29. WHO. Insecticides resistance in malaria vectors: overview of resistance status. 2017. http://www.who.int/gho/malaria/insecticide_resistance/ monitoring/en/. Accessed 04 March 2017.

30. National Malaria Control Programme. Plan stratégique national de lutte contre les épidémies de paludisme, 2006-2010. Ministère de la santé et des affaires sociales. 2005. (In French) http://31.3.96.8/fr/downloads/doc_ download/1238-plan-strategique-national-de-lutte-contre-les-epidemies-depaludisme-2006.html. Accessed 26 June 2017. 
31. Ould Ahmedou Salem MS, Mint Lekweiry K, Mint Hasni M, Konate L, Briolant S, Faye O, et al. Characterization of anopheline (Diptera: Culicidae) larval habitats in Nouakchott, Mauritania. J Vector Borne Dis. 2013;50:302-6.

32. WHO. Test procedures for insecticide resistance monitoring in malaria vectors, bio-efficacy and persistence of insecticides on treated surfaces. Geneva: World Health Organization; 2013.

33. Abbott WS. A method of computing the effectiveness of an insecticide. J Econ Entomol. 1925;18:265-7.

34. Le Goff G, Boussès P, Julienne S, Brengues C, Rahola N, Rocamora G, Robert V. The mosquitoes (Diptera: Culidae) of Seychelles: taxonomy, ecology, vectorial importance, and identification keys. Parasit Vectors. 2012;5:207.

35. Santolamazza F, Mancini E, Simard F, Qi Y, Tu Z, et al. Insertion polymorphisms of SINE200 retrotransposons within speciation islands of Anopheles gambiae molecular forms. Malar J. 2008;7:163.

36. MR4 Staff, Huynh L. Kdr-knockdown resistance in Anopheles gambiae. In: Methods in Anopheles Research. Centres for Disease Control. 2015. https:// www.beiresources.org/Portals/2NectorResources/ 2016\%20Methods\%20in\%20Anopheles\%20Research\%20full\%20manual.pdf). Accessed 04 Jan 2017.

37. MedCalc Statistical Software version 16.4.3. MedCalc Software bvba. Ostend, Belgium; 2016. https://www.medcalc.org

38. Weir BS, Cockerham CC. Estimating F-statistics for the analysis of population structure. Evolution. 1984;38:1358-70.

39. Niang EHA, Konaté L, Diallo M, Faye O, Dia I. Patterns of insecticide resistance and knock down resistance ( $k d r)$ in malaria vectors An. arabiensis, An. coluzzii and An. gambiae from sympatric areas in Senegal. Parasit Vectors. 2016;9:71.

40. Ibrahim SS, Riveron JM, Stott R, Irving H, Wondji CS. The cytochrome P450 CYP6P4 is responsible for the high pyrethroid resistance in knockdown resistance-free Anopheles arabiensis. Insect Biochem Mol Biol. 2016;68:23-32.

41. Nwane P, Etang J, Chouaibou M, Toto JC, Koffi A, Mimpfoundi R, et al. Multiple insecticide resistance mechanisms in Anopheles gambiae s.l. populations from Cameroon, Central Africa. Parasit Vectors. 2013;6:41.

42. Djegbe I, Boussari O, Sidick A, Martin T, Ranson H, Chandre F, et al. Dynamics of insecticide resistance in malaria vectors in Benin: first evidence of the presence of L1014S kdr mutation in Anopheles gambiae from West Africa. Malar J. 2011;10:261.

43. Badolo A, Traore A, Jones CM, Sanou A, Flood L, Guelbeogo WM, et al. Three years of insecticide resistance monitoring in Anopheles gambiae in Burkina Faso: resistance on the rise? Malar J. 2012;11:232.

44. Ndiath MO, Cailleau A, Orlandi-Pradines E, Bessell P, Pagès F, Trape JF, et al. Emerging knockdown resistance in Anopheles arabiensis populations of Dakar, Senegal: first evidence of a high prevalence of kdr-e mutation in West African urban area. Malar J. 2015;14:364.

45. Dabiré RK, Namountougou M, Diabaté A, Soma DD, Bado J, Toé HK, et al. Distribution and frequency of $k d r$ mutations within Anopheles gambiae s.l. populations and first report of the Ace1 G119S mutation in Anopheles arabiensis from Burkina Faso (West Africa). PLoS One. 2014;9:e101484.

46. Nwane P, Etang J, Chouaibou M, Toto JC, Kerah-Hinzoumbé C, Mimpfoundi $R$, et al. Trends in DDT and pyrethroid resistance in Anopheles gambiae s.s. populations from urban and agro-industrial settings in southern Cameroon. BMC Infect Dis. 2009;9:163.

\section{Ready to submit your research? Choose BMC and benefit from:}

- fast, convenient online submission

- thorough peer review by experienced researchers in your field

- rapid publication on acceptance

- support for research data, including large and complex data types

- gold Open Access which fosters wider collaboration and increased citations

- maximum visibility for your research: over $100 \mathrm{M}$ website views per year

At BMC, research is always in progress.

Learn more biomedcentral.com/submissions 